\title{
LA-UR-21-27710
}

Approved for public release; distribution is unlimited.

Title: Gleaming new facility delivers expertise now and into the future

Author(s): $\quad$ Lunn, Maureen Elizabeth

Intended for: Share with customers

Issued: 
Disclaimer:

Los Alamos National Laboratory, an affirmative action/equal opportunity employer, is operated by Triad National Security, LLC for the National Nuclear Security Administration of U.S. Department of Energy under contract 89233218CNA000001. By approving this article, the publisher recognizes that the U.S. Government retains nonexclusive, royalty-free license to publish or reproduce the published form of this contribution, or to allow others to do so, for U.S. Government purposes. Los Alamos National Laboratory requests that the publisher identify this article as work performed under the auspices of the U.S. Department of Energy. Los Alamos National Laboratory strongly supports academic freedom and a researcher's right to publish; as an institution, however, the Laboratory does not endorse the viewpoint of a publication or guarantee its technical correctness. 


\section{Gleaming new facility delivers expertise now and into the future}

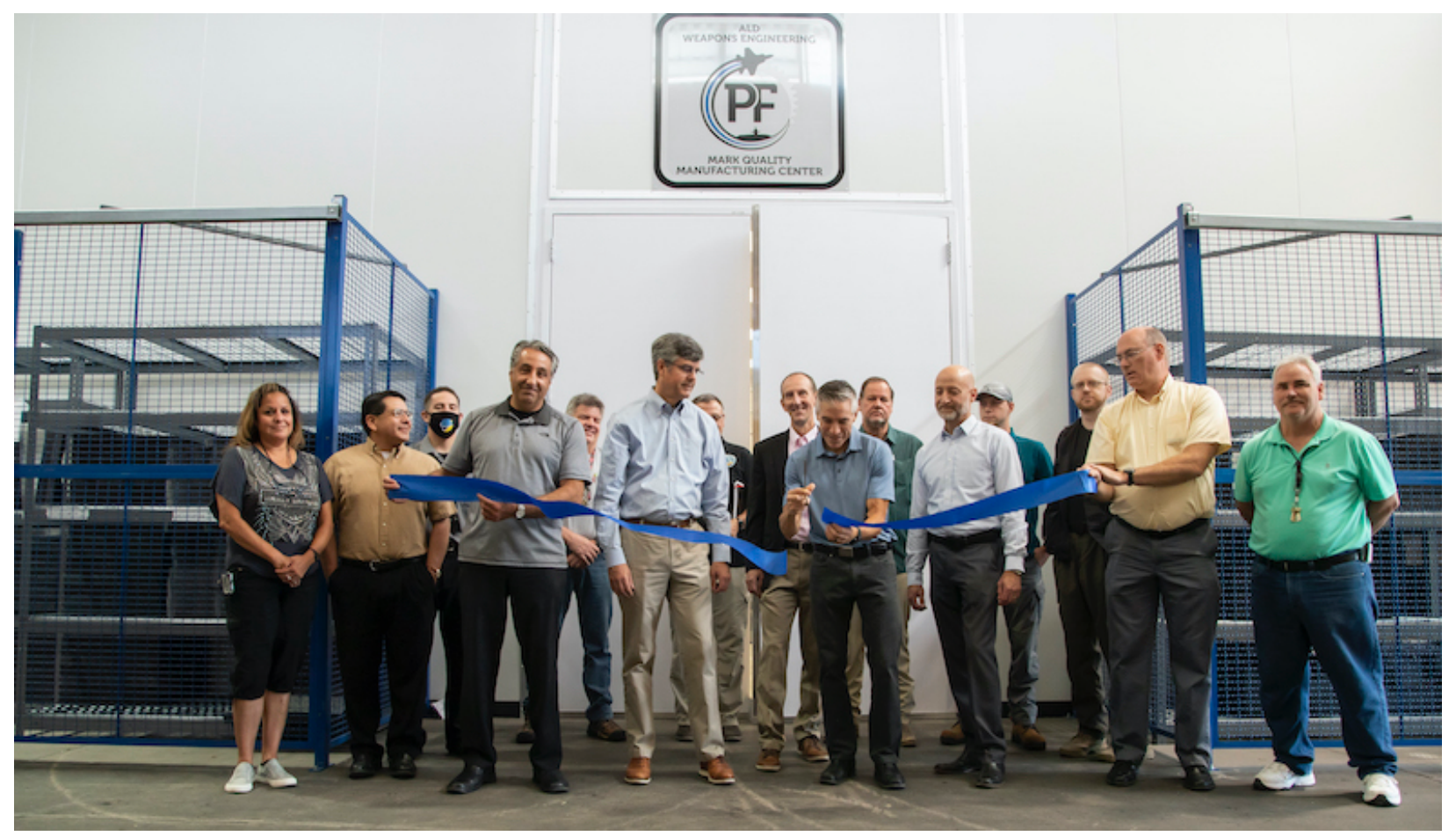

Randy Flores (PF-PROD) officially cuts the ribbon for the Mark Quality Manufacturing Center as Director Thom Mason and Prototype Fabrication leadership look on.

On Tuesday, July 27, leadership from the Prototype Fabrication (PF) division welcomed a band of machinists, managers, project managers, members of Lab leadership, and NNSA to celebrate the official opening of a facility like no other at the Laboratory, and unique across the globe.

The Mark Quality Manufacturing Center (MQMC) was developed throughout 2020 in support of weapons production capabilities, and is the Lab's new home for high-precision non-nuclear components manufacturing. Work has been occurring there for several months, but with pandemic restrictions easing, it was finally time to celebrate.

\section{'Each member brought unique talent'}

The Prototype Fabrication division is under the non-nuclear operations umbrella of the weapons production directorate (ALDWP). In November 2018, it was given the task of producing parts for the W88 Alt940. Having previously manufactured similar products, PF division had demonstrated their capability for the high-precision work that would be required - but the space to do it was another story. 
This was going to take a village.

So a village they gathered, from project managers to machinists, to vendors and contractors and employees from all around the Laboratory. Collaboration would be the key to the success of this project - no less when the pandemic shutdown hit in March 2020.

Randy Flores is the technical project manager for the MQMC, and emphasized the significance of the dedicated employees who not only worked on-site amidst the early months of the COVID pandemic, but did so with respect for the precautions and safety guidance in place.

"The ModLab [a part of the facility] was entirely constructed during the pandemic," Flores said. "The team respected safety protocols and always kept each other's health at the forefront. I think it pulled the team together even closer."

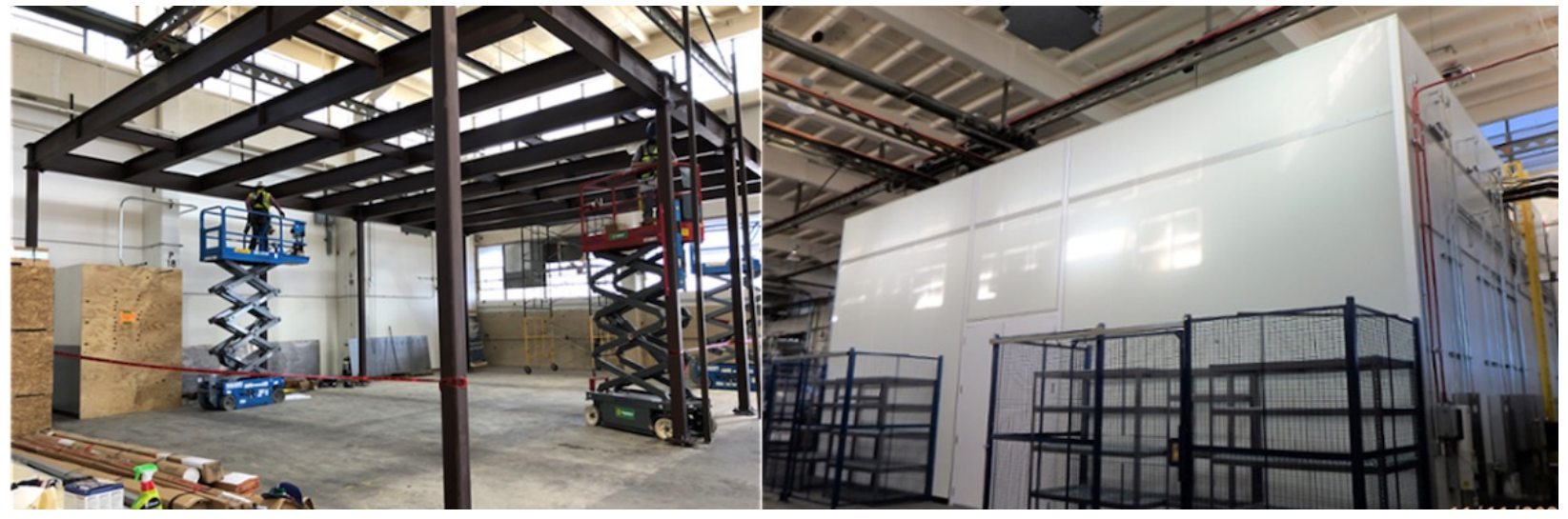

Before and after of the modular metrology laboratory, or ModLab, which is one key part of the overall MQMC. Learn about the ModLab here.

At the celebration event, PF division leader Kevin Saeger expressed the crucial levels of collaboration employed by people across the Lab. The core team of project managers were supported by Weapons Research Services, quality and inspection employees, procedure writers, and more. They were standing up an entirely new capability. "Each member brought unique talent to the team," Saeger said.

\section{A world-class capability}

Francisco Lopez (PF-PROD) is a Lean Six Sigma Black Belt in PF. He manages the quality system for MQMC. He also tracks the process performance for all the components MQMC fabricates, an approach that is helping the team to produce parts with high precision and accuracy, and consequently, deliver zero-defects to NNSA. At the event, he expressed that the new fabrication processes will save $70-90 \%$ in dimensional inspection time in coming years as employees work under Six Sigma principles to continuously improve on the exacting standards 
of manufacturing for the stockpile. Here are some examples of MQMC's approach to continuous improvement and operational excellence.

For example, MQMC fabricates and assembles 18 individual components for the W88 Alt940 mission, verifies over 730 dimensional customer requirements per assembly, and will produce several assemblies per month in support of the Alt940 mission.

"This is world-class manufacturing," Francisco said. "What we've done over the last two years is truly remarkable."

Learn about the journeyman machinists working in PF.

\section{Delivering precision and reliability for our national security}

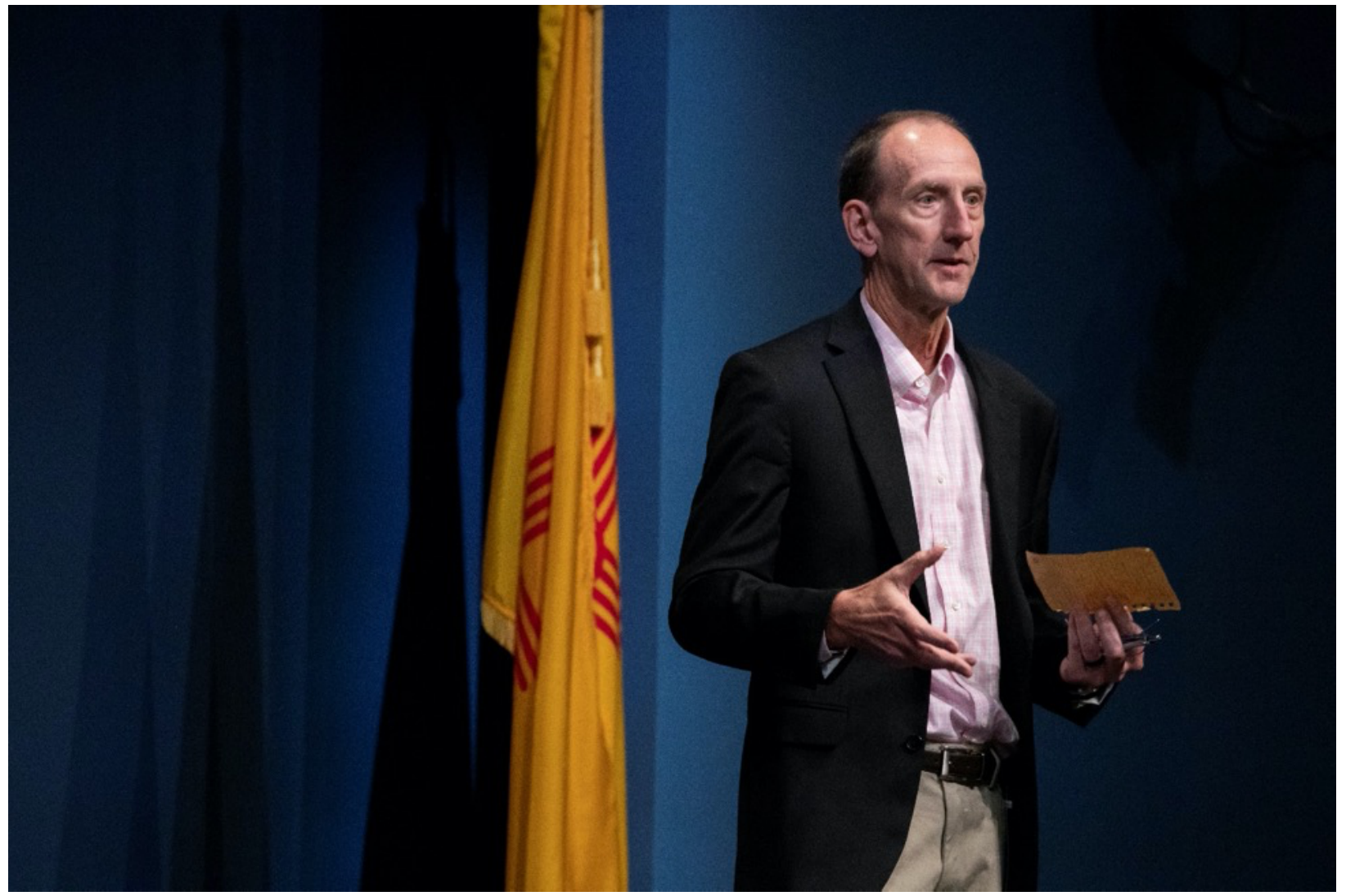

Kevin Saeger, PF's division leader, thanks a long list of people and organizations around the Lab who made the MQMC a success.

Overall, the MQMC team procured and installed more than 14 new major pieces of manufacturing equipment (like the Mazak i300), installed the infrastructure for classified computing, delivered development components to show capability, passed multiple NNSA 
reviews, created more than 40 new processes and procedures, and demonstrated $98 \%$ process yield in their first few months of manufacturing in the new space.

It all came together in less than two years, amidst a global pandemic.

"I'm incredibly happy to be here today," said James Owen, associate laboratory director for weapons engineering. "In just two years we have a world-class manufacturing capability. I'm really proud of that, and I can see your pride and ownership of it, too. Thank you for your work on this critical project for our nation's stockpile."

Published in LANLToday on August 3, 2021 